\title{
SUBOCLUZIA DUODENALĂ INTERMITENTĂ LA COPIL. STUDIU CLINIC ŞI RADIOLOGIC
}

\section{Dr. Bauer Adalbert, medic primar pediatru, doctor în medicină, SCM Caritas Medica}

\section{Discuții.}

Malformațiile congenitale ale duodenului şi ale organelor abdominale supramezocolice învecinate pot întreține procese patologice la nivelul acestui segment digestiv, de exemplu: stază, procese inflamatorii, ocluzii parțiale sau totale cu caracter temporar sau permanent.

Sub aspectul formelor anatomice, aceste anomalii sunt polimorfe, atât din punct de vedere lezional, structural, cât şi din punct de vedere al simptomatologiei clinice. Practicienii pediatri sunt mai puțin familiarizați cu aceste noțiuni patologice şi mai ales cu rolul pe care îl au în suferința abdominală cronică a copilului.

Tabloul clinic al stenozei duodenale în perioadă neonatală poate fi identificat fără dificultăți deosebite, mai ales de un practician versat în patologie neonatală.

Subocluziile parțiale sau cu caracter intermitent însă prezintă un grad de dificultate deosebită privind precizarea diagnosticului, chiar şi de prezumpție.

Această zonă de vârf în patologia abdominală cronică organică la copil, din punct de vedere semiologic prezintă un polimorfism impresionant de multe ori indescifrabil prin varietatea conexiunilor clinice şi fiziopatologice.

Aceste malformații congenitale ale cadrului duodenal sau ale organelor învecinate, pot evolua mult timp asimptomatic, dar pot întreține un disconfort digestiv exprimat prin dureri abdominale recidivante, cronice, procese de indigestie trenante -sindrom dispeptic duodenal- vărsături ocazionale de diferite intensități culminînd uneori cu vărsături incoercibile însoțite de deshidratări intempestive. Revin şi suliniez faptul că aceste vărsături prezintă caractere clinice identice cu vărsăturile acetonemice ale copilului preşcolar şi şcolar, arhicunoscute de practicienii pediatri.

În afară de simptomele clinice semnalate copilul este sănătos, cu dezvoltarea psihosomatică normală, corespunzătoare vârstei.

Identificarea anomaliei duodenale are loc fie printr-o intervenție chirurgicală efectuată pentru alte motive sau altă afecțiune chirurgicală -apendicită acută sau cronică, ocluzie intestinală- sau poate fi o curiozitate anatomopatologică depistată la autopsie.

Totuşi trebuie subliniat că pe aceşti copii îi însoțeşte toată viață un disconfort digestiv din cauza stazei duodenale. În unele cazuri sunt intercalate tablouri clinice asemănătoare cu un abdomen acut de tip ocluziv cu tentativă de intervenție chirurgicală imediată şi amânată după calmarea respectiv amendarea simptomatologiei clinice.

Eminentul chirurg francez Massardier aminteşte de un bolnav de 41 de ani care a fost operat pentru o malformație congenitală a cadrului duodenal şi care a mărturisit următoarele: „eu de mic copil mănânc, sufăr şi vărs”.

\section{Fiziopatologia}

Mecanismul de producere al acestor subocluzii duodenale congenitale se datorează unor defecte de rotație ale ansei duodenale şi de coalescență peritoneală. Ele sunt cunoscute ca malrotații sau malpoziții duodenale (duoden mobil parțial sau total, duoden inversat, mezenter comun, megaduoden, angulații anormale ale cadrului duodenal). 
Alteori bridele congenitale duodeno-cecale sau bridele colice drepte (bridele Ladd) pot fi cauza subocluziei. De exemplu coalescența exagerată a unghiului Treitz poate stenoza segmentul duodeno-jejunal. Îngroşarea ligamentului cistico-duodeno-colic şi cudurile pe care le întreține pot ocluziona duodenul.

Herniile para-duodenale, hiatul Winslow, fosetele peritoneale, apar şi ele între cauzele subocluziilor.

Între cauzele vasculare sunt amintite: vena portae preduodenale şi vena portae prepancreatica. Tot mai mult se publică (Taylor-Hyde-Szabo) despre tabloul clinic furnizat de pensarea arterei mezenterice a cadrului duodenal la copii şcolari şi adolescenți.

În cadrul unui studiu pe un lot de 213 copii privind rolul modificărilor duodeno-vesiculopancreatice în afecțiunile abdominale cronice la copil, am înregistrat 6 cazuri de ocluzii duodenale forme clinice persistente, progresive sau intermitente.

În cele ce urmează mă voi referi doar la subocluzii duodenale intermitente (în total 3 cazuri) de variantele anatomice, studiul clinic şi tratamentul lor.

Subliniez faptul că nu am găsit referiri în literatura pediatrică contemporană despre studiul clinic al acestui tablou nosologic.

\section{Studiul clinic}

În cele trei cazuri din observația noastră în care copiii au întrunit simptomele clinice de suspiciune prezentate mai jos, am efectuat examinări radiologice cu tehnici perfecționate în vederea confirmării sau infirmării diagnosticului de subocluzie duodenală.

Simptomatologia clinică se caracterizează prin următoarele:

- după consum de mese copioase apar vărsături incorcibile - în reprize -

- vărsăturile sunt însoțite de dureri abdominale de tip colicativ şi cu localizare în regiunea epigastrică sau hipocondrul drept.

- vărsăturile conțin alimente nedigerate, conținut bilios în unele cazuri, ocazional sanguinolent.

- instalarea rapidă a sindromului de deshidratare acută, însoțit de astenie şi hipotonie marcată a copilului

- distensie epigastrică de diferite intensități

- unde peristaltice moderate

Conform observațiilor noastre aceşti copii nu reacționează la tratamentul clasic al vărsăturilor ciclice acetonemice, evoluția lor este anevoioasă, timpul de vindecare prelungit.

O parte din cazuri ajung la servicii de chirurgie cu suspiciune de abdomen acut chirurgical, dar în lipsă de indicație absolută intervenția suferă amânare, starea copilului se ameliorează treptat, devine asimptomatic, iar noi suntem dispuşi să etichetăm cazul ca o afecţiune digestivă acută supramesocolică sau o formă mai severă de gastrită sau gastro-duodenită. Ulterior totuşi majoritatea ajung pe masa de operație până la 15-16 ani.

\section{Concluzii}

În practica pediatrică sunt două situații în care se impune efectuarea unor explorări radiologice de finețe cu tehnici perfecționate (examen radiologic standard sau selectiv, duodenografie hipotonă cu tub sau fără tub cu substanțe farmacodinamice -codeină, antrenyl).

\section{1 - În prima varianta clinică}

- depăşirea limitei de vârstă caracteristică pentru vărsături acetonemice ciclice (apariția sau repetarea acestora peste $8-9$ ani)

\section{2 - În a doua variantă}


- la grupa de vârstă caracteristică pentru vărsături acetonemice, cu îndeplinirea următoarelor condiții clinice:

- debut brusc, după mese copioase

- vărsături bilioase, cu alimente deloc digerate

- distensie epigastrică, discret peristaltism epigastric

- dureri abdominale colicative puternice sau silențioase

- ineficiența tratamentului clasic al vărsăturilor acetonemice

(evoluție mai anevoiasă, prelungită, cu refacerea „ad integrum” a

copilului în mai mult de 8-10 zile).

\section{Prezentare de caz - cu iconografia radiologică}

Prezint pe scurt cazul cel mai instructiv şi cu iconografia radiologică evocatoare.

Elevul V.I. în vârsta de 15 ani, s-a prezentat la serviciul nostru, pentru dureri abdominale recidivante, си crize de vărsături periodice, incoercibile cu deshidratări intempestive, apărute la intervale nedeterminabile, cu debut de la vârsta preşcolară.

Cazul a fost etichetat de-a lungul anilor la nivelul diferitelor eşaloane sanitare ca vărsătură acetonemică, cu toate că reacția la tratamente clasice pentru această afecțiune a fost mai anevoioasă, cu periode de recuperare mai lungi. În momentul consultării copilului am semnalat un meteorism abdominal pronunțat cu localizare epigastrică, cu discrete unde peristaltice.

Având în vedere datele anamnestice, simptomatologia clinică neconcordantă cu vărsături acetonemice, faptul că acuzele au persistat până la vârsta de 15 ani, adică peste limita de vârstă caracteristică a vărsăturilor acetonemice, am pus în discuție o obstrucție intermitentă a duodenului, având la bază şi experiența altor cazuri.

Am propus examinări radiologice atât clasice, cât şi cu tehnici perfecționate.

\section{1 - Examenul baritat gastro-intestinal}

Stomacul este hipoton cu peristaltism superficial şi lent, evacuare spontană-megabulb, duoden mult dilatat cu stază pronunțată, stop prelungit pe D III juxta-genunchiului inferior. Bariul apare în jejun după decubit lateral drept la 20 de minute. (Figura a)

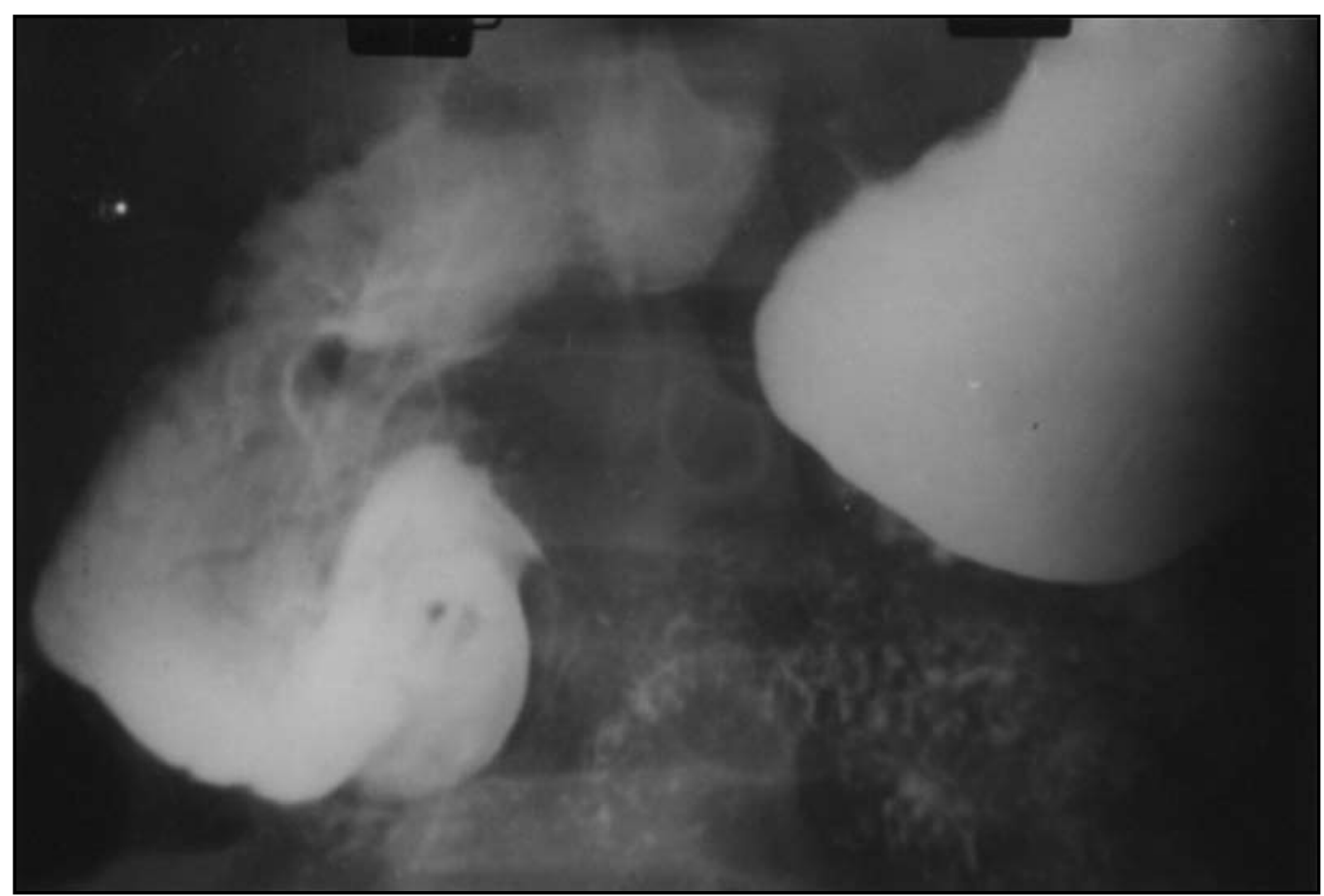

Figura a 


\section{2 - Explorarea radiologică selectivă a duodenului.}

În vederea elucidării etiologiei stenozei duodenale, am efectuat explorarea selectivă a duodenului cu bariu introdus prin sondă duodenală asociată cu probă cu codeină. Examinarea a fost executată de eminentul radiolog şi bun prieten al meu, regretatul DR. Lorinczy Dengezics.

Pe seriografiile efectuate în decubit şi procubit, porțiunea duodenală după stopul descris la examenul baritat simplu, face o torsiune elicoidală de 720 de grade în plan sagital, în interiorul cadrului, după care continuă traiectul obişnuit până la flexura lui TreitzR. (Figura b., c./ vârful sondei se poate vedea pe ultimul clişeu al Fig.c)

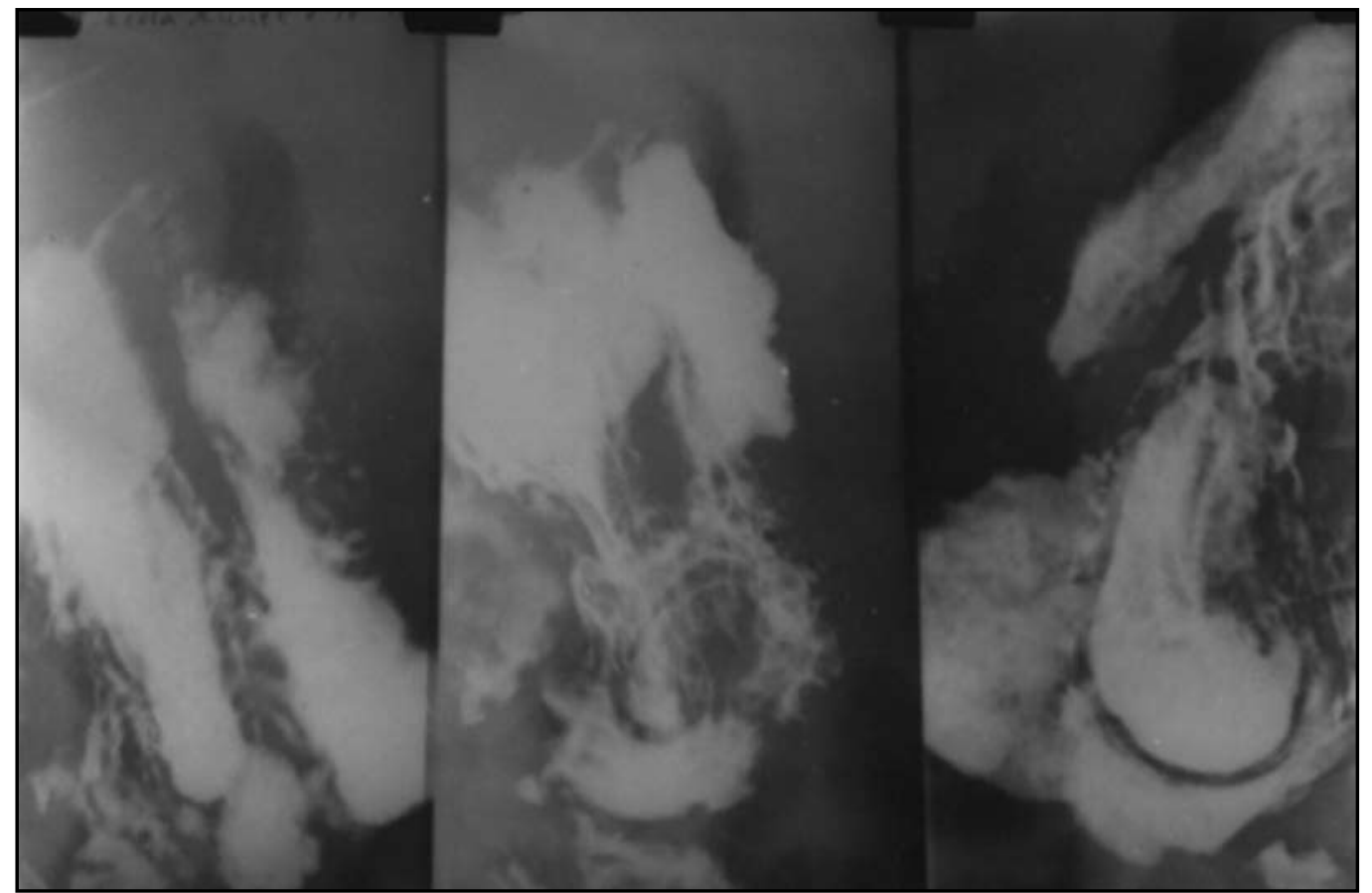

Figura $b$

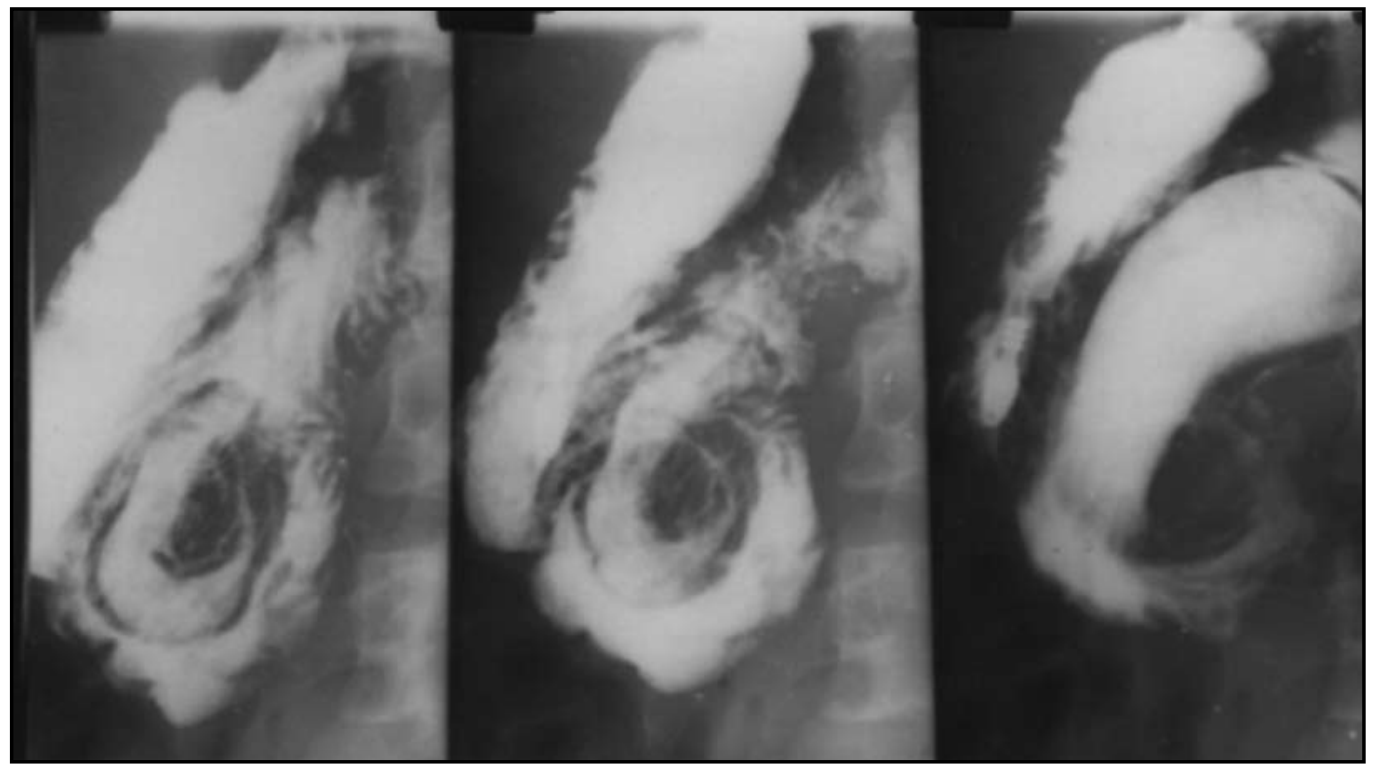

Figura c

3 - Colecistografia intravenoasă cu Pobilan $\mathbf{5 0} \%$ evidențiază o implantare joasă a coledocului, cu diskinezie hipotonă moderată a veziculei biliare. (Figura d., e.) 


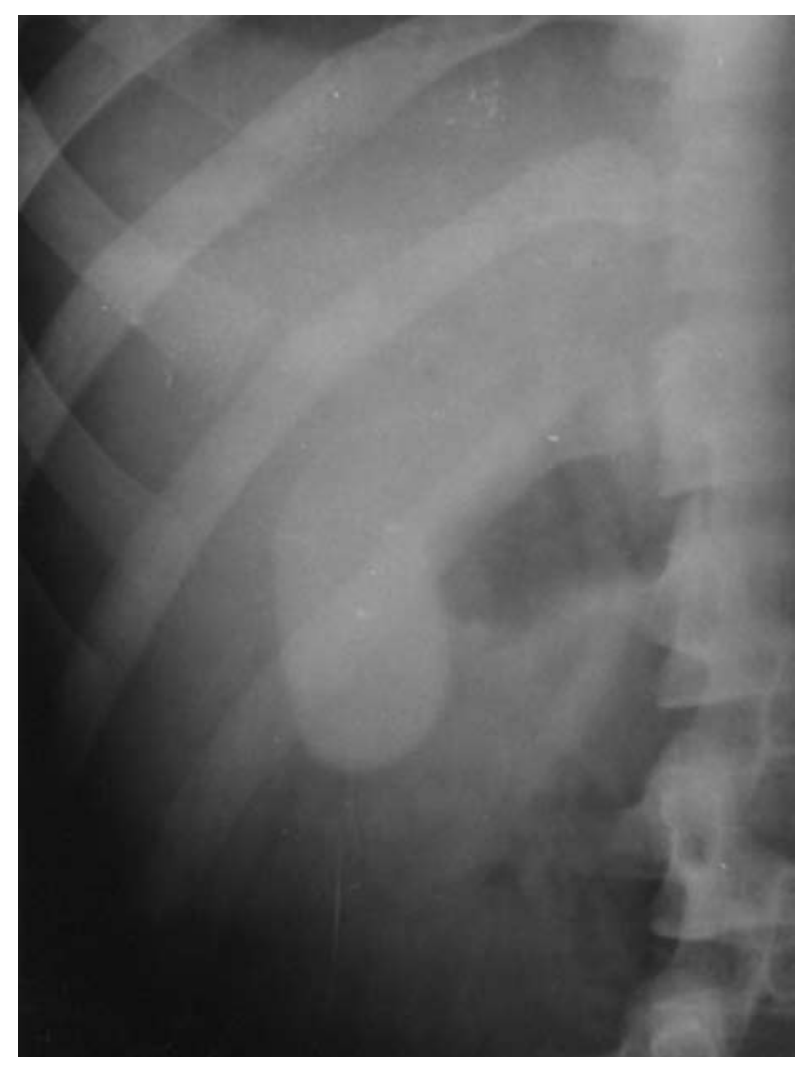

Figurad

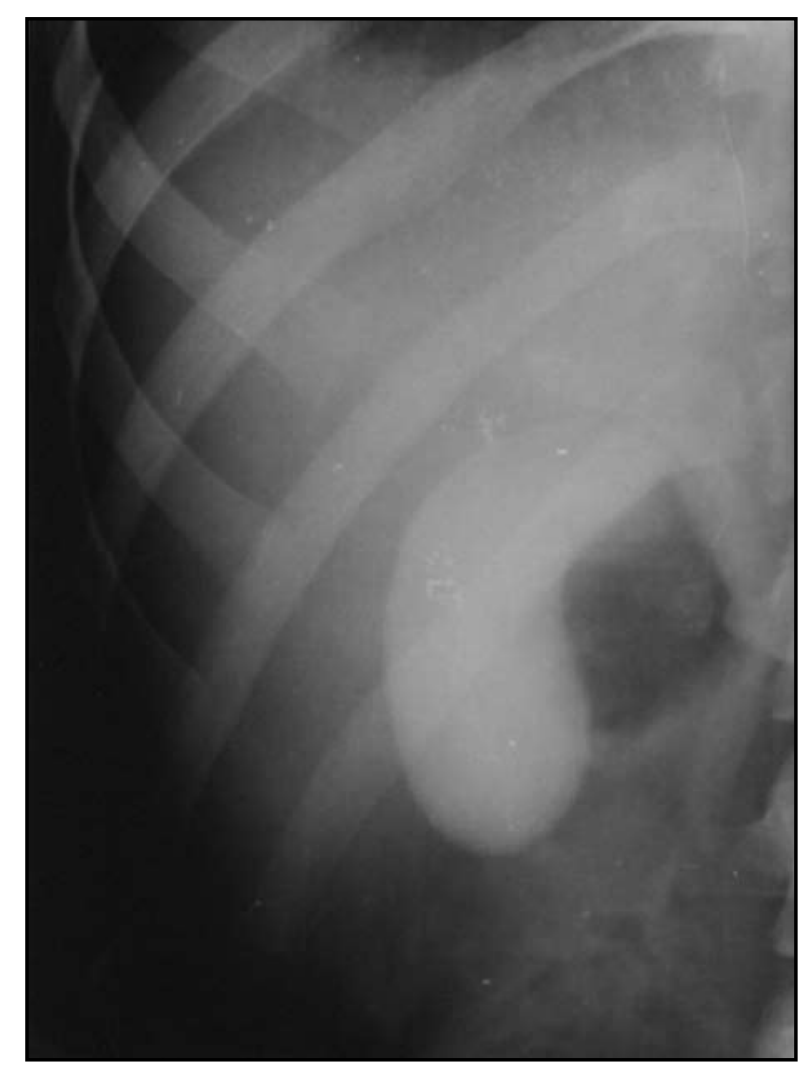

Figura e

Diagnosticul radiologic - Stenoză duodenală incompletă extraluminală, malformație congenitală a cadrului duodenal pe segmentul D III. Hernie retroperitoneală paraduodenală. Implantarea joasă a coledocului.

Diagnostic clinic - Subocluzie duodenală intermitentă, pe fond de malformație a cadrului duodenal, cu vărsături acetonemice simptomatice.

\section{Bibliografie}

1. Adam, E. E. - Udroiu.v.: Diverticuli duodenali - în Medicină internă Bucureşti - 5-631, 1978

2. Aitren, I.: Congenital intrinsec duodenal obstruction in infancy - în Pediat. Surg - 1-546-348, 1986

3. Andriu, I, Caramagiu, D.: Chirurgia duodenului - Editura Medicală - Bucureşti-1963

4. Ansaldi, M, Balocco, A.: Utilite de la duodenograhie hipotonique chez l'enfant - în Minerva Pediatrica-2335-1441-1444, 1971

5. Arnold. C.: Tumeurs du duodenum - în Hyg.Geneve-976-1351, 1980

6. Balaban, I., Tărărescu, C.: Stenozele duodenale la copii- Oncologia şi Radiologia-4-289-299, 1969

7. Banzet, P: Duodenum mobile - în Arch.Mal.App: Digest XVIII 4-379

8. Bartent, M. K.: The surgical menagament of paraduodenal hernia - în Ann.Surg. 168-249, 1979

9. Becker, Car., Becker, E: Ergebnisse simultaner Rontgen Untersuchung von gallenblase, magen und duodenum - în Radiology Diagnostics-6-557-565, 1979

10. Berger, M.: Ein Fall von Duodenum Duplication - în Kinder-Artzliche-Praxis-106-109, 1966

11. Berens, I. J.: Small internal hernies in the paraduodenal aria - în Arc.Surg.-86-726, 1966

12. Bîrzu, I., Vulcănescu, E.: Radiologia clinică a duodenului patologic neulceros-Editura Medicală - Bucureşti-50-51 
13. Boles, E. T.: Paraduodenal portal vein - în Pediatrics - 25-1879-1888,1975

14. Brombart, M.: Les affections du duodenum - Sem.Hop.Paris-1208-1209, 1979

15. Caffey, J.: Pediatric X-RAY diagnosis - Zork-Book. Medication -Publ - Chicago

16. Deli, I., Berkovics, I.: A duodenum vizsgálat LIOTTA féle módszere - în Magyar Radiologia.

17. Fancalsrud, E. W.: Congenital atreszia and stenosis of the duodenum - în Pediatrics-1-79-83, 1969

18. Engelholm, L.: Le duodenograhie hypotonique - în Acta-Belgica-Gastroenterologica-35-120-136, 1979

19. Figarella, V.: Stenoze duodenale congenitale prin bride - în Chirurgia 178-183 Editura Medicală Bucureşti

20. Prouty, E.: Duodenal compresion by the mesenteric artery - în J.Pediat. 50-6-734, 1967. 